\title{
Balancing of specific nutrients and subsequent growth and body composition in the slug Arion lusitanicus
}

\author{
Kim Jensen a,b,c,*, Sabine Engelke ${ }^{\mathrm{d}}$, Stephen J. Simpson ${ }^{\mathrm{b}}$, David Mayntz ${ }^{\mathrm{d}}$, John Hunt ${ }^{\mathrm{c}}$ \\ a Department of Zoology, University of Oxford, South Parks Road, Oxford OX1 3PS, UK \\ b School of Biological Sciences, University of Sydney, Heydon-Laurence Building A08, Sydney, NSW 2006, Australia \\ ' Centre for Ecology and Conservation, College of Life and Environmental Sciences, University of Exeter, Cornwall Campus, Penryn TR10 9EZ, UK \\ d Department of Bioscience, Ecology and Genetics, Aarhus University, Building 1540, 8000 Aarhus C, Denmark
}

\section{H I G H L I G H T S}

- Slugs were restricted to nutritionally variable diets or given a choice.

- Food intake and nutrient utilization were affected by diet nutrient balance.

- Slugs given a choice were able to maximize growth.

- High dietary carbohydrate to protein ratio limited growth but increased fat mass.

\section{A R T I C L E I N F O}

\section{Article history:}

Received 16 April 2013

Received in revised form 11 August 2013

Accepted 28 August 2013

\section{Keywords:}

Carbohydrate:protein balance

Geometric framework

Invasive species

Mollusca

Optimal foraging

Protein leverage hypothesis

\begin{abstract}
A B S T R A C T
Feeding generalists typically occupy broad ecological niches and so are potentially pre-adapted to a range of novel food objects. In northern Europe, the slug Arion lusitanicus has spread rapidly as an invasive species and a serious horticultural and agricultural pest. We used nutritional geometry to analyze nutrient balancing capabilities and consequences for performance in A. lusitanicus when provided with one of three nutritionally fixed diets or when given dietary choice. The slugs over-ingested high amounts of the most abundant nutrient in order to get more of the limited nutrient. However, they regulated protein intake more tightly than carbohydrate intake resulting in a very high food intake when fed a protein-poor diet. Growth and body composition were highly affected by the nutrient balance of their diet. When given the choice to feed from two nutritionally different diets, the slugs selected an intake balance of protein and carbohydrate with sufficient precision to maximize growth. Nutrient utilization efficiency increased with increasing deficiency of the specific nutrient in the diet. Ingested carbohydrate was more efficiently stored as lipid in slugs fed more carbohydrate-poor diets, and ingested nitrogen was more efficiently incorporated into slug bodies in slugs fed more protein-poor diets. Our experiments suggest that the evolved behavioral and physiological regulatory capacities of A. lusitanicus may explain some of the success that this slug experiences as an invasive species. We furthermore propose that invasive species might be more dependent on high protein availability in the environment than non-invasive species.
\end{abstract}

(c) 2013 Elsevier Inc. All rights reserved.

\section{Introduction}

Optimal foraging theory predicts that animals have evolved foraging mechanisms that maximize their fitness [1]. The traditional approach to optimal foraging has centered around finding sufficient food, how long to reside in one patch before moving on to search for a more lucrative one, and trading off foraging behavior against the risk of predation. These studies have typically focussed on the acquisition of a single

\footnotetext{
* Corresponding author at: Centre for Ecology and Conservation, College of Life and Environmental Sciences, University of Exeter, Cornwall Campus, Penryn TR10 9EZ, UK. Tel.: + 441326 371872; fax: + 441326253638.

E-mail address: k.jensen@exeter.ac.uk (K. Jensen).
}

currency, often energy [1]. However, an increasing number of studies have shown that animals will actively regulate their intake of specific nutrients and that the composition of nutrients rather than the total amount determines consumption and performance [2].

The Geometric Framework for Nutrition has over the years proven to be a powerful tool to disentangle the interactive effects of specific nutrients on animal feeding behavior [2,3]. It has also been applied to study physiological regulation of specific nutrients after ingestion [4,5], and the most recent trend has been to link specific nutrient intake to performance $[6,7]$. Whereas nutritional geometry has now been applied in different areas of research including conservation $[8,9]$, obesity [10,11], aging and lifespan [12,13], and immune function [14], the framework has not been applied in the context of describing the nutritional requirements and balancing capacities of invasive species. This 
would provide insight into the behavioral and physiological mechanisms that these animals possess, which might explain some of the reason why invasive species thrive in novel environments where food objects are often novel as well.

The slug Arion lusitanicus Mabille 1868 (synonym: Arion vulgaris Moquin-Tandon 1955) has spread rapidly over the last two decades and now occurs as an invasive species throughout northern Europe $[15,16]$. The slugs are considered a major pest, causing damage to agricultural and horticultural plants with reductions of crop yields by up to $50 \%[17,18]$, and are listed as one of the most important invasive animals in Europe $[19,20]$. The species was recently described to be robust and have a high phenotypic plasticity as it continued reproducing under environmentally challenging conditions [21]. It furthermore has high impact on ecosystem dynamics by consuming and out-competing other species $[22,23]$. In addition to the common notion that $A$. lusitanicus deter large amounts of plant material, the slugs are observed to feed selectively when provided with a buffet of different species of plants [16,24-27], indicating either nutrient balancing behavior or detergent avoidance. Using artificial diets, another common pest slug, Deroceras reticulatum, was shown to forage selectively for nutritionally complementary food after nutritional restriction [28]. They did so regardless of added detergent content in the diets, supporting the view that slugs forage to balance their intake of nutrients.

We used nutritional geometry to analyze the nutrient balancing behavior and the consequences of specific nutrient intake for growth and body composition in juvenile $A$. lusitanicus. We then investigated postingestive nutrient regulation by analyzing the efficiency of incorporating specific ingested nutrients into body tissue. Our study provides basic information on the nutrient balancing behavior and physiology of $A$. lusitanicus and thereby on the nutritional requirements and plasticity of this invasive species.

\section{Materials and methods}

\subsection{Animals and housing}

Adult A. lusitanicus were collected at a single site in Aarhus, Denmark, in late August and allowed to lay eggs in the laboratory. All hatchlings emerged within a span of a few days. They were maintained in an incubator at $5{ }^{\circ} \mathrm{C}$ and a $12 \mathrm{~h}$ light: $12 \mathrm{~h}$ dark regime and provided with carrots, cucumber and dog food for 1 month until the start of experiments. Three days before experiment start, all food was removed and the temperature was raised to $18{ }^{\circ} \mathrm{C}$ where it remained during the experiments. At setup, all slugs were weighed to the nearest $\mu \mathrm{g}$ and distributed at random to experimental treatments. During experiments the slugs were housed individually in transparent plastic boxes $(15 \mathrm{~cm}$ length, $10 \mathrm{~cm}$ width, $5 \mathrm{~cm}$ height) containing a water saturated sponge to maintain $100 \%$ humidity and a piece of white chalk to ensure coverage of calcium requirements.

\subsection{Experimental design}

A no-choice and a choice experiment were conducted simultaneously over eight weeks using three semi-synthetic diets (Table 1) manufactured in pellet form by Altromin GmbH (Germany). A full ingredient list for the diets is presented in Table S1. In the no-choice experiment, a total of 45 slugs each received only one of the three diets throughout the experiment, while in the choice experiment a total of 30 slugs were each given the choice to feed from two of the three diets (three dietary combinations) throughout the experiment. Since we found no effect of diet on survival (no-choice: $\chi^{2}=0.56, d f=2, P=0.76$; choice: $\chi^{2}=1.40$, $d f=2, P=0.50$ ), slugs that died during experiments were excluded from the analysis. After mortality that occurred during the 8 week feeding period, our final sample sizes were 7 slugs on the $9 \%$ P diet, 11 slugs on the $31 \% \mathrm{P}$ diet and 12 slugs on the $48 \% \mathrm{P}$ diet in the no-choice experiment and
Table 1

Nutritional compositions (mass based) of the three artificial diets used in the two feeding experiments. Ingredient compositions are presented in Table S1.

\begin{tabular}{llll}
\hline Components & $9 \% \mathrm{P}$ & $31 \% \mathrm{P}$ & $48 \% \mathrm{P}$ \\
\hline Crude protein (\%) & 9.0 & 31.4 & 47.7 \\
Carbohydrate (\%) & 71.8 & 49.5 & 33.1 \\
Crude lipid (\%) & 7.8 & 7.6 & 7.7 \\
Crude fiber (\%) & 6.0 & 6.0 & 6.0 \\
Ash (\%) & 5.4 & 5.5 & 5.4 \\
Carbohydrate:protein & $8: 1$ & $1.6: 1$ & $0.7: 1$ \\
Energy content (kJ/g) & 16.0 & 16.0 & 16.0 \\
\hline
\end{tabular}

The diets also contained mineral mix $\left(\mathrm{K}_{2} \mathrm{CO}_{3}\right.$, Coal. Chalk, $\mathrm{NaCl}, \mathrm{MgCl}_{2}, \mathrm{~K}_{2} \mathrm{HPO}_{4}, \mathrm{Fe}_{2} \mathrm{O}_{3}$, $\mathrm{FeSO}_{4}, \mathrm{MnSO}_{4}, \mathrm{NaF}, \mathrm{KI}, \mathrm{Na}_{2} \mathrm{SeO}_{3}, \mathrm{Na}_{2} \mathrm{MoO}_{4}, \mathrm{CoCl}_{2}, \mathrm{ZnCO}_{3}, \mathrm{CuSO}_{4}$ ), and a vitamin mix (C 1000, Altromin).

8 slugs on the 9\%P vs. 31\%P diet pair, 10 slugs on the 9\%P vs. 48\%P diet pair and 7 slugs on the $31 \% \mathrm{P}$ vs. $48 \% \mathrm{P}$ diet pair in the choice experiment.

\subsection{Experimental procedures}

Diet was provided by the start of the experiment and renewed every seventh day. Diet was provided on a glass dish (19 mm diameter, $5 \mathrm{~mm}$ height). In the choice experiment we placed each glass dish with diet inside an inverted Petri dish lid (35 mm diameter, $5 \mathrm{~mm}$ height) to prevent diet mixing. Diets were kept in a drying oven at $60{ }^{\circ} \mathrm{C}$ for at least three days before weighing and were weighed to the nearest milligram on the glass dish before and after the seven day feeding period. Any feces were removed from the glass dishes before weighing. Diet intake was calculated as the difference in diet dry mass before and after feeding, and specific nutrient intakes were calculated using the known proportions of protein and carbohydrate in the diets. All slugs were weighed by the end of the experiments. They were then left for two days without food to discard gut contents before they were again weighed and killed by freezing at $-20{ }^{\circ} \mathrm{C}$.

\subsection{Body nutrient analysis}

Each slug was dried at $60{ }^{\circ} \mathrm{C}$ over four days and weighed to the nearest milligram. Lipids were then extracted during five 24-h washes in $10 \mathrm{ml}$ petroleum ether. After again drying the slugs at $60{ }^{\circ} \mathrm{C}$ over four days and reweighing, the lipid mass of each slug was calculated by subtracting the lipid extracted, lean dry mass from the dry mass. The slugs were then pulverized using mortar and pestle and the mass based proportion of nitrogen in a subsample of 4-6 mg pulverized slug was analyzed in a dry combustion analyzer (Na 2000, Carlo Erba, Italy). The total nitrogen content of each slug was calculated by multiplying the proportion of nitrogen in the subsample with the slug lean dry mass. The crude protein mass of each slug was then calculated by multiplying body nitrogen mass by 6.25 [29].

\subsection{Statistical analyses}

\subsubsection{No-choice experiment}

We examined differences in the dry mass intake and the growth of slugs across the different diets using a multivariate analysis of variance (MANOVA) for repeated-measures [30]. In this model, we included diet (fixed effect), time (repeated measure) and their interaction. As there were three diet treatments, we ran pair-wise comparisons between the dietary treatments to determine which of them that contributed significantly to overall significant effects. One-way analysis of variance (ANOVA) with Tukey's HSD post-hoc tests were also conducted at each time period to show over which feeding periods the main differences in dietary intake and growth occurred. For each feeding period, we estimated the slope of the cumulative protein vs. carbohydrate intake array across diets $\left(\beta_{\mathrm{a}}\right)$ using linear regression and tested this against a hypothetical slope $\left(\beta_{\mathrm{h}}\right)$ of -1 using a $t$-test where $\left(\beta_{\mathrm{a}}-\beta_{\mathrm{h}}\right) /\left(\mathrm{SE}_{\beta \mathrm{a}}\right)$ 
approximates a $t$-distribution with $n=2$ degrees of freedom [31]. A slope of -1 indicates a constant combined intake of the two nutrients as well as a constant intake of energy, as protein and carbohydrate contain the same amount of energy by mass $(\sim 16.7 \mathrm{~kJ} / \mathrm{g})$. In contrast, a slope different from -1 indicates that one nutrient was regulated more tightly than the other and energy intake differed across diets. We compared the change in slope of the intake array over time using linear regression and the variation in the total intake of protein and carbohydrate using a Levene's test.

\subsubsection{Choice experiment}

We analyzed the intake of each diet in our three diet pairs in two ways. First, we used a paired $t$-test to compare if slugs consumed more of one diet in the pair than the other within each feeding period and in total. We analyzed the intake of diets and specific nutrients (protein and carbohydrate) using the repeated-measures MANOVA and post-hoc analyses outlined above for the no-choice experiment. Separate models were run for each nutrient. Second, we used repeatedmeasures ANOVA to examine the change in the intake of each diet per diet pair across feeding periods. This analysis partitions the observed variance in dietary intake into variation within the same slug and between different slugs. A significant within diet pair variation suggests that dietary preferences of one diet versus the other varies over time, whereas a significant between diet pair variation suggests that slugs in different food pairings differ in their preference of one diet over the other. A significant within by between slug interaction suggests that the pattern in food preferences changes differently over time in the three treatments.

As both dietary intake and subsequent growth of slugs was highest on the $31 \% \mathrm{P}$ diet in the no-choice experiment, we analyzed whether the regulated intake point differed from that expected if slugs fed exclusively on the $31 \% \mathrm{P}$ diet. The regulated intake point was calculated as the mean total $\mathrm{P}$ and $\mathrm{C}$ intake of slugs across our three diet pairs. Based on the total amount of diet eaten by each slug, we calculated the expected intake of $\mathrm{P}$ and $\mathrm{C}$ if slugs had consumed the same amount of the $31 \% \mathrm{P}$ diet. This expected intake of $P$ and $C$ was then subtracted from the observed intake of these nutrients and the difference tested against a mean of zero using a one sample $t$-test. Differences in slug growth on the different diet pairs were examined using the same repeated measures MANOVA procedure and post-hoc tests used in the no-choice experiment. We then compared the growth of slugs in the choice experiment to that of slugs restricted to each of the single diets in the nochoice experiment using a repeated-measures MANOVA and post-hoc tests as outlined above. As slug growth did not differ between the choice diet pairs, we pooled the growth data of all slugs in the choice experiment before we compared them to the growth data on each of the three no-choice treatments in the no-choice experiment.

\subsubsection{Body composition and post-ingestive nutrient utilization}

We examined differences in lipid and crude protein content of slugs in the six treatment groups from both experiments using MANOVA. ANOVAs were used to determine which of the response variables contributed significantly to the overall multivariate effect, and Tukey's HSD post-hoc tests were used to contrast each of the six diet treatments. To examine differences in the utilization efficiency of protein in the six treatment groups, we used analysis of covariance (ANCOVA) with treatment included as the main effect, protein intake as the covariate, and the interaction between the main effect and covariate, with crude protein content as the response variable. The same ANCOVA model was used to examine the utilization efficiency of carbohydrate, except that carbohydrate intake was used as the covariate and lipid content was the response variable. We similarly analyzed the utilization efficiency of ingested energy including energy intake as the covariate and lipid content as the response variable. To determine how the slope of the relationship between the covariate and the response variable differed across treatments, we conducted pair-wise comparisons between treatments using student's $t$-test [31] calculated as $t=\left(b_{1}-b_{2}\right) / s_{b 1}-b 2$ where $b_{1}$ and $b_{2}$ are the slopes of diet 1 and 2, respectively, and $s_{b 1}-b 2$ is the standard error of the difference between regression coefficients, calculated as $s_{b 1-b 2}=\sqrt{\left(\left(s^{2} y, x\right)_{p} /\left(\sum x 2\right)_{1}\right)+\left(\left(s^{2} y, x\right)_{p} /\left(\sum x 2\right)_{2}\right)}$ where $\left(s_{y, x}^{2}\right)_{p}$ is the pooled residual mean square calculated as $\left(s^{2} y, x\right)=\left(s s_{\text {residual }}\right)_{1}+$ $\left(s s_{\text {residual }}\right)_{2} /\left(d f_{\text {residual }}\right)_{1}+\left(d f_{\text {residual }}\right)_{2}$. The degrees of freedom $(d f)$ for the test is $\left(n_{1}-2\right)+\left(n_{2}-2\right)$, where $n_{1}$ and $n_{2}$ are the sample sizes in diet 1 and 2 , respectively.

\section{Results}

\subsection{Balancing of protein and carbohydrate intake under no-choice}

Food intake differed significantly with the diet provided and over time with a significant interaction between the two (Fig. 1A, Table 2). The slugs on average ingested more when feeding on the intermediate $31 \% \mathrm{P}$ diet, less when feeding on the $48 \% \mathrm{P}$ diet and least when feeding on the $9 \%$ P diet over the experiment (Fig. 1A, Table 2 ), with statistically significant differences on a weekly basis from the sixth week of feeding (Fig. 1A). The consumption of the intermediate 31\%P diet increased at a faster rate over time compared to both the $9 \% \mathrm{P}$ and the $48 \% \mathrm{P}$ diet, whereas the rate of increase did not differ between the $9 \% \mathrm{P}$ and the 48\% P diet (Fig. 1A, Table S2).

Slugs that were restricted to a single imbalanced diet would have to balance the over-ingestion of one of the two nutrients that varied in the experiment against the under-ingestion of the other. Over the early weeks of feeding, the intake array did not differ significantly from a slope of -1 (Fig. 2). Over time, however, the slope became progressively
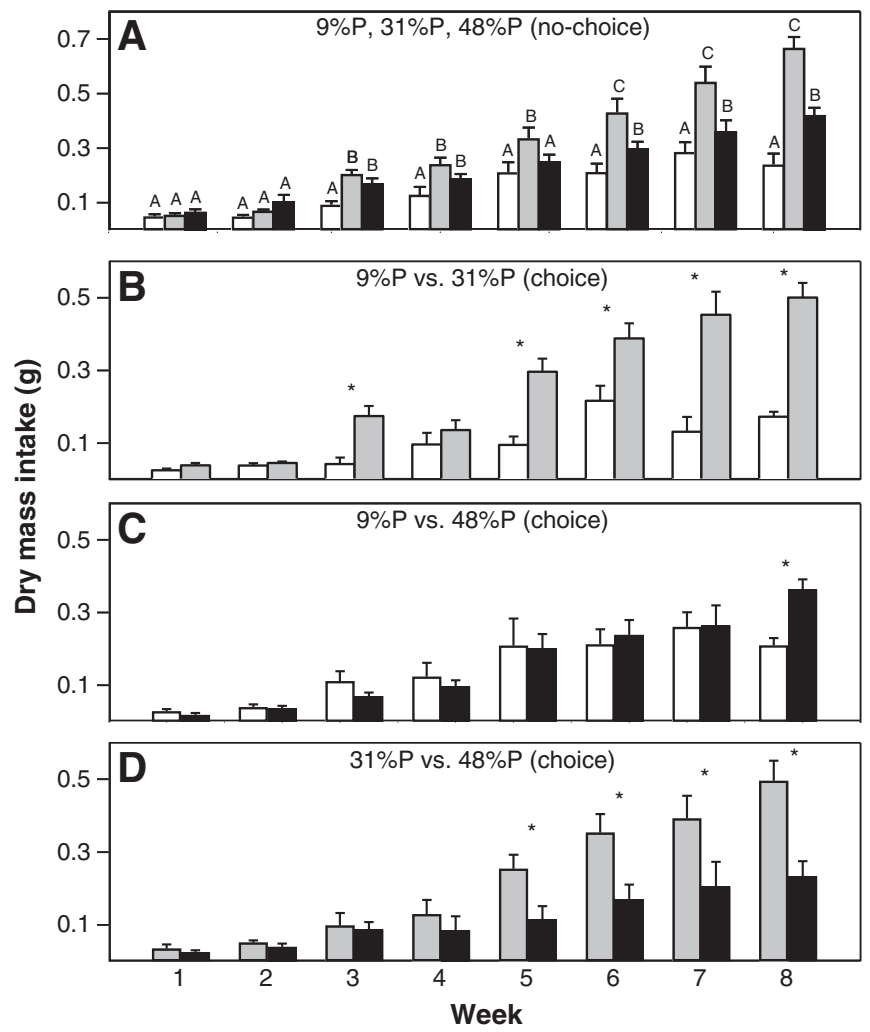

Fig. 1. Intake (mean $\pm \mathrm{SE}$ ) of the 9\%P diet (white), the 31\%P diet (gray) and the 48\%P diet (black) by the juvenile A. lusitanicus over each week of the experiments. (A) Intake by slugs restricted to single diets in the no-choice experiment. Different letters indicate significant differences $(P<0.05)$ using Tukey's HSD post-hoc tests. (B-D) Intake of each diet by slugs given the opportunity to feed from two of the three diets in the choice experiment. Asterisks indicate significantly different $(P<0.05)$ consumption from the two diets using paired $t$-tests. (B) $9 \%$ P vs. $31 \%$ P. (C) $9 \%$ Ps. $48 \%$ P. (D) $31 \%$ Ps. $48 \%$ P. 
Table 2

Repeated-measures multivariate analysis of variance (MANOVA) on examining the effects of diet and time, plus their interaction, on the intake of diets by slugs in the no-choice experiment. Univariate post-hoc analyses for each diet pair are presented in Table S2.

\begin{tabular}{llrl}
\hline \multirow{2}{*}{ Model } & \multicolumn{2}{l}{ MANOVA } & \\
\cline { 2 - 4 } & $F$ & $d f$ & $P$ \\
\hline Diet & 12.916 & 2,17 & 0.0001 \\
Time & 47.845 & 7,21 & 0.0001 \\
Diet $\times$ time & 4.772 & 14,42 & 0.0001 \\
\hline
\end{tabular}

more negative $(\beta \pm \mathrm{SE}=-0.161 \pm 0.017)$, and was significantly greater than -1 after the seventh and eighth week of feeding (linear regression, $t_{7}=9.651, P<0.0001$, Fig. 2 ). The steep slope by the end of the experiment reveals that the total protein intake by the end of the experiment varied significantly less than the total carbohydrate intake across all slugs feeding on a single diet (Levene's test: $F_{1,58}=$ 5.97, $P=0.018$; coefficient of variation $(C V): C V_{\text {protein }}=42.66 \%$, $C V_{\text {carbohydrate }}=47.92 \%$ ). This indicates that the slugs over time regulated their protein intake more tightly than they regulated their carbohydrate intake. Because we used iso-caloric diets, the greater than -1 slope of the intake array also demonstrates that the slugs did not eat to maintain equal energy intake across diets (Fig. 2).

Both diet and time significantly affected slug body mass with a significant interaction between the two (Fig. 3A, Table 3). Post-hoc analysis showed that, on average, slugs attained more body mass on the intermediate $31 \% \mathrm{P}$ diet, less on the $48 \% \mathrm{P}$ diet and least on the $9 \% \mathrm{P}$ diet, with significant differences after 6 weeks of feeding (Fig. 3A, Table S3). Slugs feeding on the intermediate $31 \% \mathrm{P}$ diet had higher growth rates than slugs feeding on both the 48\% diet and the $9 \% \mathrm{P}$ diet, and the growth

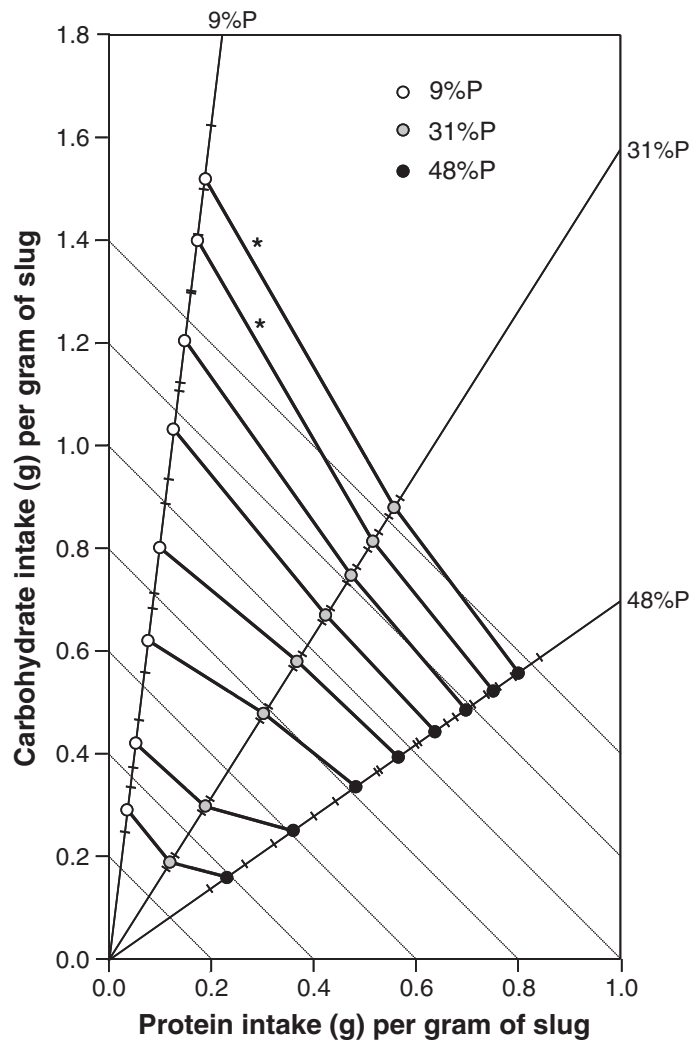

Fig. 2. Cumulative protein and carbohydrate intake (mean $\pm S E$ ) over each week for the slugs in the no-choice experiment. The slopes of the straight lines starting from the origin show the carbohydrate:protein ratios of the three diets and thus the nutrient ratios the slugs were restricted to ingest. Asterisks indicate intake arrays (bold lines) that are significantly $(P<0.05)$ steeper than a slope of -1 (dashed lines) using linear regression.

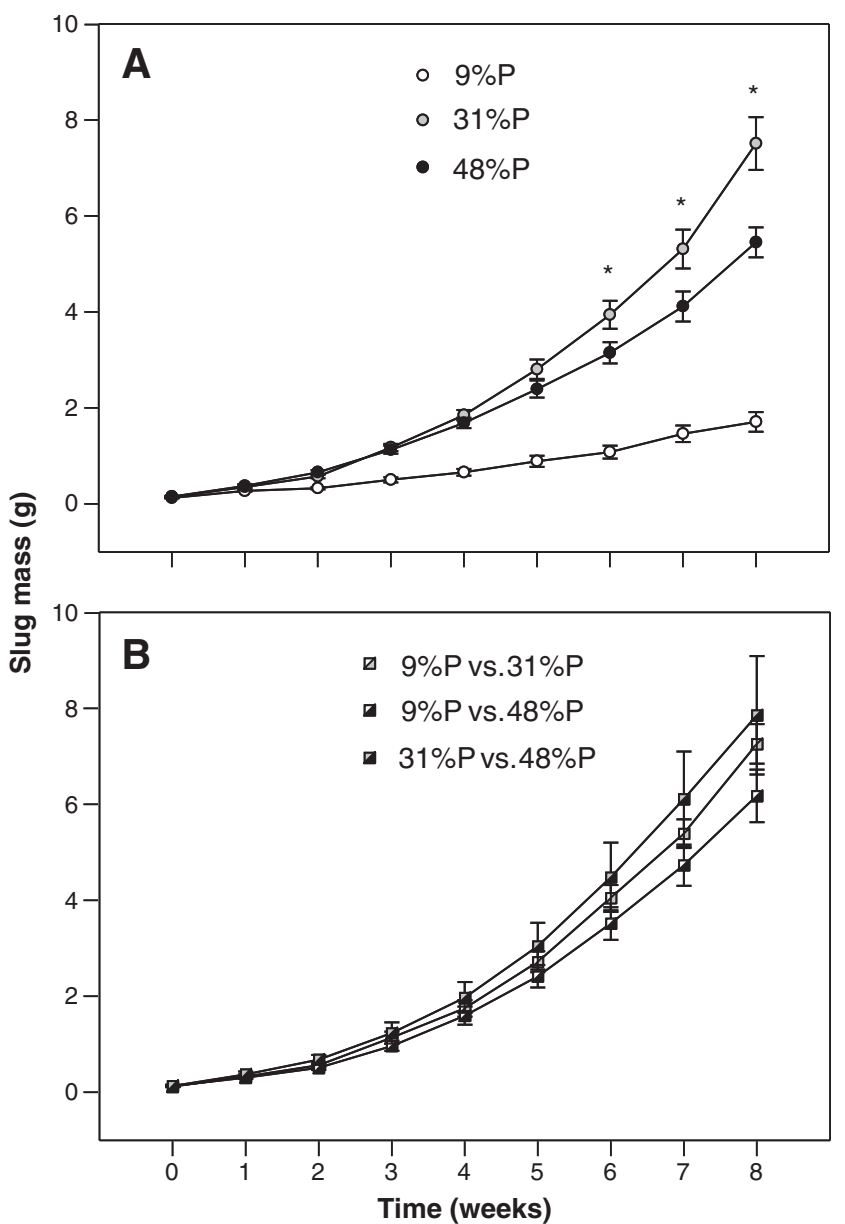

Fig. 3. Slug mass (mean \pm SE) across feeding periods in (A) the no-choice experiment and (B) the choice experiment. Asterisks indicate significant mass differences $(P<0.05)$ between all three dietary treatments using Tukey's HSD post-hoc test.

rates of slugs feeding on the $48 \% \mathrm{P}$ diet were higher than those of slugs feeding on the 9\% diet (Fig. 3A, Table S3). The slugs on the 9\% diet were thus far from reaching full growth compensation despite their very high compensatory feeding behavior (Fig. 2) and remained very small compared to the other slugs (Fig. 3A).

\subsection{Balancing of protein and carbohydrate intake under choice}

When two diets were provided, the slugs had the chance to balance the intake of protein and carbohydrate by eating different amounts from the two diets in order to attain any specific nutrient intake within the span of the nutrient ratios of the two diets. When provided with the 9\%P diet and the 31\% diet, we found a significantly higher diet intake from the 31\% diet than from the 9\%P diet over the experiment (paired $t$-test: $t_{8}=7.12, P=0.0002$ ), with significant differences within most weeks (Fig. 1B). When provided with the $9 \% \mathrm{P}$ diet and the $48 \% \mathrm{P}$ diet,

Table 3

Repeated-measures MANOVA on examining the effects of diet and time, plus their interaction, on the growth of slugs in the no-choice experiment. Univariate post-hoc analyses are presented in Table S3.

\begin{tabular}{llrl}
\hline Model & \multicolumn{2}{l}{ MANOVA } & \\
\cline { 2 - 4 } & $F$ & $d f$ & $P$ \\
\hline Diet & 33.249 & 2,27 & 0.0001 \\
Time & 65.330 & 8,20 & 0.0001 \\
Diet $\times$ time & 6.521 & 16,20 & 0.0001 \\
\hline
\end{tabular}


however, total intake from the two diets did not differ significantly (paired $t$-test: $t_{10}=0.76, P=0.47$ ) and did not differ within feeding weeks except for last week of feeding (Fig. 1C). When provided with the 31\% P diet and the 48\% P diet, the slugs again significantly preferred eating from the 31\%P diet (paired $t$-test: $t_{7}=5.90, P=0.0011$ ) with significant differences from the fifth week (Fig. 1D). Within all three diet pairs, slugs provided with the same pair of diets did not differ in their preference (repeated-measures ANOVAs: $P>0.24$ ) but only increased intake over time as they grew larger (repeated-measures ANOVAs: $P<0.0001)$.

Diet pair provided and time both significantly affected the intake of protein and carbohydrate with a significant interaction between the two (Fig. 4, Table 4). The slugs consumed more protein when given the $31 \% \mathrm{P}$ vs. $48 \% \mathrm{P}$ diet pair than when given the $9 \% \mathrm{P}$ vs. $31 \% \mathrm{P}$ or the $9 \%$ vs. $48 \%$ P diet pair, while there was no difference in protein intake between the two latter diet pairs (Fig. 4, Table S4). The overall effect of time on protein intake was caused by an increased consumption of protein over time on all diet pairs, and the overall interaction between diet pair and time on protein intake was caused by a faster increasing protein intake rate when given the $31 \% \mathrm{P}$ vs. $48 \% \mathrm{P}$ diet pair than when given the $9 \% \mathrm{P}$ vs. $31 \% \mathrm{P}$ diet pair (Fig. 4 , Table S4). In contrast, slugs given the $9 \% \mathrm{P}$ vs. $31 \% \mathrm{P}$ diet pair consumed more carbohydrate than slugs given the $9 \% \mathrm{P}$ vs. $48 \% \mathrm{P}$ diet pair and the $31 \% \mathrm{P}$ vs. $48 \% \mathrm{P}$ diet pair, while slugs given the $9 \% \mathrm{P}$ vs. $48 \% \mathrm{P}$ diet pair consumed more carbohydrate than slugs given the $31 \% \mathrm{P}$ vs. $48 \% \mathrm{P}$ diet pair (Fig. 4, Table S4). The overall effect of time on carbohydrate intake was caused by an increased consumption of carbohydrate over time on all diet pairs, and the overall interaction between diet pair and time on carbohydrate intake was caused by a faster increasing carbohydrate intake rate when given the $9 \% \mathrm{P}$ vs. $31 \% \mathrm{P}$ diet pair and the $9 \% \mathrm{P}$ vs. $48 \% \mathrm{P}$ diet pair than when given the $31 \% \mathrm{P}$ vs. $48 \% \mathrm{P}$ diet pair (Fig. 4, Table S4). The regulated

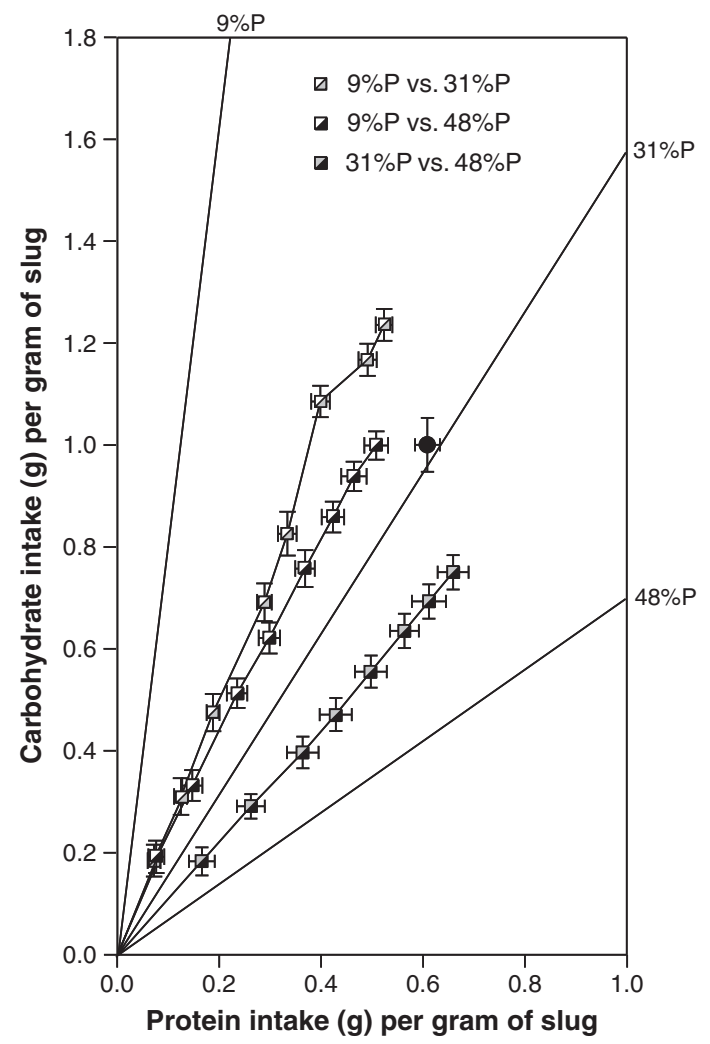

Fig. 4. Cumulative protein and carbohydrate intake (mean $\pm \mathrm{SE}$ ) over each week for the slugs in the choice experiment. The line connecting each cumulative intake point indicates the nutrient intake trajectory selected by the slugs. The black circle shows the overall regulated intake point (mean $\pm \mathrm{SE}$ ) of the three choice treatments combined.
Table 4

Repeated-measures MANOVA on examining the effects of diet pair and time, plus their interaction, on the intake of protein and carbohydrate by slugs in the choice experiment Univariate post-hoc analyses are presented in Table S4.

\begin{tabular}{lrrl}
\hline Model & MANOVA & \\
\hline Protein & \multicolumn{4}{l}{ df } & $P$ \\
Diet pair & 9.696 & 2,22 & 0.001 \\
Time & 392.417 & 7,16 & 0.0001 \\
Diet pair $\times$ time & 2.379 & 14,32 & 0.021 \\
Carbohydrate & $F$ & $d f$ & $P$ \\
Diet pair & 35.578 & 2,22 & 0.0001 \\
Time & 276.476 & 7,16 & 0.0001 \\
Diet pair $\times$ time & 3.106 & 14,32 & 0.004 \\
\hline
\end{tabular}

intake point, estimated as the average protein and carbohydrate intake across the three diet pairs, did not differ significantly from expected intake if the slugs had been restricted to feed on the 31\%P diet (protein: $t_{24}=1.90, P=0.070$; carbohydrate: $t_{24}=1.90, P=0.070$, Fig. 4 ), which maximized slug growth in the no-choice experiment (Fig. $3 \mathrm{~A}$ ).

In contrast to the no-choice slugs, growth of the choice slugs was not significantly influenced by diet pair (repeated-measures MANOVA: $F_{2,22}=1.255, P=0.305$, Fig. 3B). Moreover, although growth increased over time on all three diet pairs (repeated-measures MANOVA: $F_{8,15}=26.147, P=0.0001$ ), this increase did not differ across the diet pairs, as the interaction term between diet pair and time was not significant (repeated-measures MANOVA: $F_{16,30}=0.589, P=0.867$, Fig. 3B).

When analyzing the pooled choice treatments as a treatment together with the three no-choice treatments, we still found significant effects of dietary treatment and time as well as of their interaction on slug growth (Table 5). Slugs given a choice between diets grew larger than those fed only with the 9\%P diet, and although growth increased with time in both treatments, slugs grew faster over time when given a choice between diets (Fig. 3, Table S5). The overall growth of slugs on the $48 \% \mathrm{P}$ diet and those given a choice between diets did not differ significantly, but although there was an increase in growth over time in both treatments, this increase was greater when slugs were given a choice between diets than when restricted to the $48 \% \mathrm{P}$ diet (Fig. 3 , Table S5). In contrast, there was no difference in growth between slugs given a choice between diets and slugs given the $31 \% \mathrm{P}$ diet. Although growth increased over time on both treatments, the rates of growth did not increase differently (Fig. 3, Table S5). In summary, slugs given a choice between diets grew larger than those restricted to the 9\% diet and faster than those restricted to the $9 \% \mathrm{P}$ or the $48 \% \mathrm{P}$ diet, but did not differ from slugs restricted to the 31\% diet, which shows that the slugs given a choice between diets were able to attain maximal growth by regulating their intake of specific nutrients.

\subsection{Body nutrient composition}

The body composition of the slugs differed significantly across dietary treatments by the end of the 8 weeks of feeding (MANOVA: Pillai's trace $=1.152, F_{10,98}=13.32, P=0.0001$, Fig. 5 ), which was due to differences in both the lipid and the protein content of the slugs (Univariate ANOVAs, lipids: $F_{5,49}=7.52, P=0.0001$; protein: $\left.F_{5,49}=61.44, P=0.0001\right)$. The body lipid and protein content of the

\section{Table 5}

Repeated-measures MANOVA on examining the effects of diet and time, plus their interaction, on the growth of slugs in the choice and no-choice experiments. Univariate post-hoc analyses are presented in Table S5.

\begin{tabular}{llll}
\hline Model & \multicolumn{2}{l}{ MANOVA } & \\
\cline { 2 - 4 } & $F$ & $d f$ & $P$ \\
\hline Diet & 14.916 & 3,51 & 0.0001 \\
Time & 53.074 & 8,44 & 0.0001 \\
Diet $\times$ time & 3.876 & 24.128 & 0.0001 \\
\hline
\end{tabular}




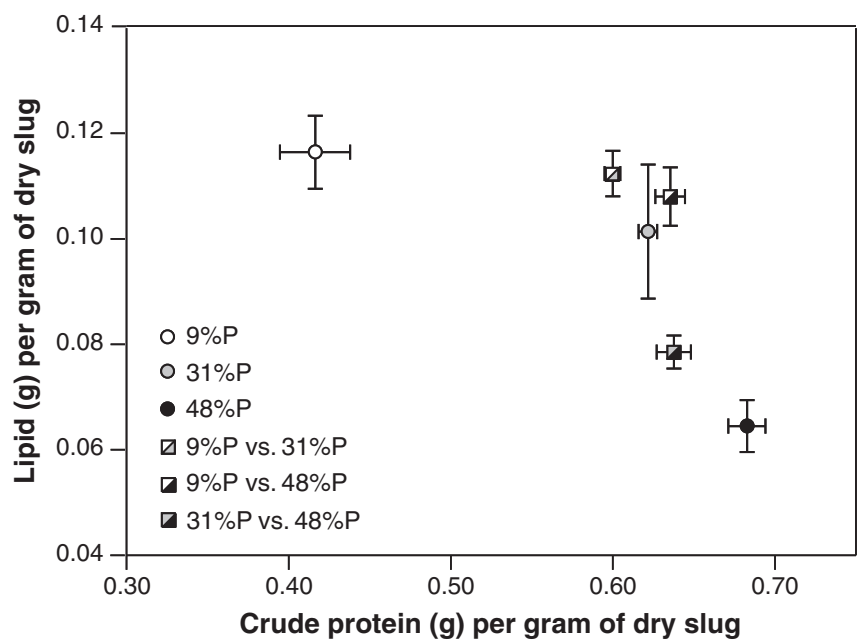

Fig. 5. Protein mass vs. lipid mass (mean \pm SE) in the dry slug bodies by the end of the experiments.

slugs thus clearly resembled the carbohydrate to protein composition of the diets they had eaten (Fig. 5). The protein content of slugs restricted to the 9\% diet was lower than that of slugs on all other diets (all $P$ 's $<0.05$ ), while the protein content of slugs restricted to the $48 \% \mathrm{P}$ diet was higher than that of slugs on all other diets (all $P^{\prime} \mathrm{s}<0.05$ ). Comparing the 31\%P treatment and the three choice treatments, the slugs provided with the $9 \% \mathrm{P}$ vs. $31 \% \mathrm{P}$ diet contained less protein than the slugs on the other three treatments $(P=0.044)$, while these did not differ significantly from each other (all $P$ 's $>0.05$ ). In accordance, the lipid content of slugs restricted to the 48\% P diet was lower than that of slugs on all other treatments (all P's $<0.05$ ). Slugs provided with the $31 \% \mathrm{P}$ vs. $48 \% \mathrm{P}$ diet pair had lower lipid content than slugs on the remaining four treatments (all $P^{\prime} \mathrm{s}<0.05$ ), while the lipid content of these (9\%P, 31\% , 9\%P vs. 31\%P and 9\%P vs. 48\%P) did not differ significantly from each other (all $P^{\prime} \mathrm{s}>0.05$ ). The high relative food intake by the slugs restricted to the protein-poor 9\% diet thus resulted in a much higher lipid to protein content in the bodies of these slugs compared to all the other slugs by the end of the experiment (Fig. 5). In contrast, the lower relative food intake by the slugs restricted to the protein-rich $48 \% \mathrm{P}$ diet resulted in a lower body lipid to protein content compared to all other slugs (Fig. 5).

\subsection{Nutrient utilization}

When analyzing protein utilization efficiency, an overall ANCOVA showed that the final protein content of slugs increased with increasing protein intake across diets $\left(F_{1,43}=33.42, P=0.0001\right)$, while there was no effect of diet treatment per se $\left(F_{5,43}=1.65, P=0.17\right)$. There was, however, a significant interaction between diet treatment and protein intake $\left(F_{5,43}=3.62, P=0.008\right)$, indicating that the slope of the relationship between protein intake and final protein content differed across diet treatments (Fig. 6A). The slope of the relationship between protein intake and final protein content was steeper for slugs restricted to the $9 \% \mathrm{P}$ diet $(t=3.03-6.07, d f=10-16, P=$ $0.011-0.0001$ ) and shallower for slugs restricted to the $48 \% \mathrm{P}$ diet $\left(t=7.12-12.14, d f=16-19\right.$, all $\left.P^{\prime} \mathrm{s}<0.0001\right)$ compared to slugs on all other diet treatments (Fig. 6A), while the slopes of this relationship did not differ among the 31\% diet and the three choice treatments $(t=1.02-1.64, d f=11-16, P=0.13-0.34)$. The slugs restricted to the protein-poor $9 \% \mathrm{P}$ diet thus incorporated ingested protein more efficiently into body tissue than slugs on all other treatments, while slugs restricted to the protein-rich $48 \% \mathrm{P}$ diet incorporated ingested protein into body tissue at a lower efficiency than slugs on all other treatments.
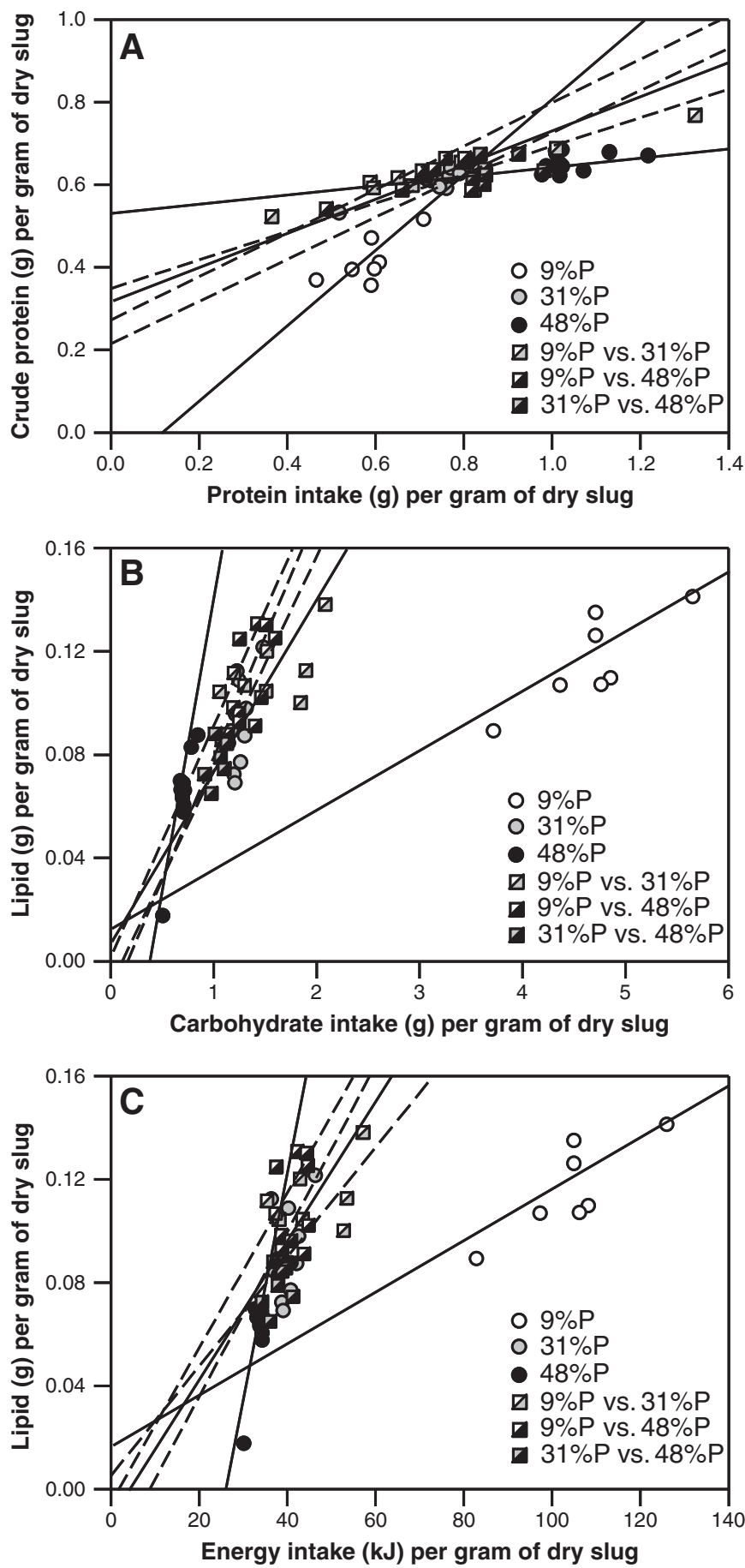

Fig. 6. Intake of specific nutrients during the experiment versus specific body nutrient content for each slug by the end of the experiment. Lines represent linear regression fits through each of the three no-choice treatments (solid) and the three choice treatments (dashed). Steeper slopes indicate higher nutrient or energy utilization efficiencies measured as the rate of incorporating ingested nutrients or energy into body tissue. (A) Protein intake vs. body protein mass. Slopes $(\beta \pm \mathrm{SE})$ of the regression lines through each dietary treatment: 9\%P: $0.58+0.11 ; 31 \% \mathrm{P}: 0.34+0.06 ; 48 \% \mathrm{P}: 0.12+0.04,9 \% \mathrm{P}$ vs. $31 \% \mathrm{P}$ : $0.24 \pm 0.0 .05$; $9 \%$ P v. $48 \%$ P: $0.32 \pm 0.09$; $31 \%$ P vs. $48 \%$ P: $0.27 \pm 0.07$. (B) Carbohydrate intake vs. body lipid mass. Slopes $(\beta \pm \mathrm{SE})$ of the regression lines through each dietary treatment: $9 \% \mathrm{P}: 0.03 \pm 0.01 ; 31 \% \mathrm{P}: 0.11 \pm 0.03 ; 48 \% \mathrm{P}: 0.21 \pm 0.02 ; 9 \% \mathrm{P}$ vs. $31 \% \mathrm{P}$ : $0.08 \pm 0.03$; $9 \%$ P vs. $48 \%$ P: $0.07 \pm 0.02$; $31 \%$ P vs. $48 \%$ P: $0.09 \pm 0.03$. (C) Energy intake vs. body lipid mass. Slopes $(\beta \pm \mathrm{SE})$ of the regression lines through each dietary treatment: $9 \% \mathrm{P}: 0.001 \pm 0.000 ; 31 \% \mathrm{P}: 0.003 \pm 0.000 ; 48 \% \mathrm{P}: 0.006 \pm 0.001 ; 9 \% \mathrm{P}$ vs. $31 \%$ P: $0.002 \pm 0.000 ; 9 \%$ vs. $48 \%$ P: $0.003 \pm 0.000 ; 31 \%$ P vs. $48 \%$ P: $0.003 \pm 0.000$ 
When analyzing how efficiently ingested carbohydrate was converted into lipids and allocated to lipid stores, ANCOVA similarly showed that the final lipid content of slugs increased with increasing carbohydrate intake across diets $\left(F_{1,43}=28.86, P=0.0001\right)$, while there was no effect of diet treatment per se $\left(F_{5,43}=1.42 .95, P=0.24\right)$. Again, there was a significant interaction between diet treatment and carbohydrate intake $\left(F_{5,43}=4.79, P=0.001\right)$, indicating that the slope of the relationship between carbohydrate intake and final lipid content differed across treatments (Fig. 6B). The slope of the relationship between carbohydrate intake and final lipid content was steeper for slugs restricted to the 48\% P diet $\left(t=8.19-22.68, d f=16-19\right.$, all $P^{\prime}$ s $\left.<0.0001\right)$ and shallower for slugs restricted to the 9\% diet $(t=7.22-20.19, d f=10-16$, all $P$ 's $<0.0001$ ), while the slopes of this relationship did not differ among the $31 \% \mathrm{P}$ and the three choice treatments $(t=0.97-1.33, d f=11-16$, $P=0.19-0.42$ ) compared to slugs on all other diet treatments (Fig. 6B). This shows that the slugs restricted to the carbohydrate-poor 48\% diet converted ingested carbohydrate more efficiently into stored lipids than slugs on all other treatments, while slugs restricted to the carbohydraterich 9\% diet incorporated ingested carbohydrate into stored lipids at a lower efficiency that slugs on all other treatments.

Qualitatively similar results were obtained when analyzing the efficiency of incorporating ingested energy into lipid stores (Fig. 6C). ANCOVA showed that the final lipid content of slugs increased with increasing energy intake across diets $\left(F_{1,43}=11.88, P=0.001\right)$, while there was no effect of diet treatment per se $\left(F_{5,43}=2.33 .95\right.$, $P=0.06)$. Again, there was a significant interaction between diet treatment and energy intake $\left(F_{5,43}=3.63, P=0.008\right)$, indicating that the slope of the relationship between energy intake and final lipid content differed across treatments (Fig. 6C). The slope of the relationship between energy intake and final lipid content was steeper for slugs restricted to the 48\%P diet $\left(t=7.65-17.12, d f=16-19\right.$, all $\left.P^{\prime} \mathrm{s}<0.0001\right)$ and shallower for slugs restricted to the 9\% $\mathrm{P}$ diet $(t=8.91-19.29$, $d f=10-16$, all $P$ 's $<0.0001)$, while the slopes of this relationship did not differ among the $31 \% \mathrm{P}$ and the three choice treatments $(t=0.43-1.01, d f=11-16, P=0.27-0.55)$ compared to slugs on all other diet treatments (Fig. $6 \mathrm{C}$ ). This shows that the slugs restricted to the carbohydrate-poor $48 \% \mathrm{P}$ diet converted ingested energy more efficiently into stored lipids than slugs on all other treatments, while slugs restricted to the carbohydrate-rich $9 \% \mathrm{P}$ diet incorporated ingested energy into stored lipids at a lower efficiency that slugs on all other treatments.

In summary, slugs restricted to feed on one of the two imbalanced diets $(9 \% \mathrm{P}$ or $48 \% \mathrm{P})$ increased the utilization efficiency of the nutrient in deficit while decreasing the utilization efficiency of the nutrient in excess compared to slugs that could ingest nutrients in balanced proportions. Likewise, when consuming a diet with increased protein content (48\%) slugs increased their energy utilization efficiency, whereas the reverse was true when consuming a diet high in carbohydrate content (9\%). These different utilization efficiencies show that regulation to reduce nutritional imbalances also occurred by adjusting physiological processes after ingestion.

\section{Discussion}

The slug A. lusitanicus occurs as an invasive species across a range of habitat types in northern Europe, where it degrades ecosystem dynamics and damages crops as it forages $[17,18]$. Here, we found that the growth and body composition of juvenile $A$. lusitanicus is highly affected by the specific nutrient composition of its diet. However, our findings also show that $A$. lusitanicus possess both behavioral and physiological mechanisms that enable them to regulate their intake and utilization of both protein and carbohydrate around an optimal balance that maximizes growth.

Studies on locusts (Locusta migratoria and Schistocerca gregaria) and armyworm caterpillars (Spodoptera littoralis and Spodoptera exempta) suggest that host-plant generalist and specialist herbivores apply different rules of compromise when encountering a nutritionally imbalanced food source [3,32-34]. Ingesting an equal mass of carbohydrate and protein across diets varying in the composition of these macronutrients is commonly associated with generalist feeders [3]. In contrast, specialist feeders tend to avoid over-ingesting the abundant nutrient relative to the intake target [3]. The intake arrays during the first six weeks of feeding by the slugs therefore conform to a nutritional rule of compromise that is typical for generalists. However, a generalized feeding ecology might reflect specialized nutritional requirements, as generalists may compose an overall balanced diet by consuming complementary imbalanced food sources.

After longer term restriction to the single diets, the intake array progressively developed a steeper slope, which demonstrates that slugs over a longer term prioritized ingesting a certain amount of protein at the cost of more variable carbohydrate intake. They were thus prepared to over-ingest large amounts of carbohydrate in order to increase protein intake when feeding on the protein-poor 9\% diet, whereas they over-ingested protein to a lower extent when feeding on the carbohydrate-poor 48\% P diet (Fig. 2). Such prioritization of protein intake at the cost of over- or under-ingestion of carbohydrate has been shown before in other omnivorous animals $[10,35]$. It is also suggested to be a key factor in the development of obesity in humans, known as the protein leverage hypothesis [10,11], and our results provide strong further evidence for this mechanism.

Our results showed that growth in A. lusitanicus is highly sensitive to nutrient balance in the diet and especially to ingesting a sufficient ratio of protein. However, animals with different life histories might not have equally specialized requirements with regards to consuming a nutritionally balanced diet. In a recent study comparing two species of Pardosa wolf spiders with dissimilar inherent growth rates, growth was severely inhibited in the species with fast growth rates when restricted to a diet with a low protein:lipid ratio, whereas growth in the species with slower growth rates was much less affected [36]. Fast growth is a trait typically associated with invasive species [37,38], and descriptions from the field indicate that $A$. lusitanicus grows very fast [16]. Growth in A. lusitanicus might therefore be more dependent on ingesting a balanced diet rich in protein compared to their non-invasive relatives.

The slugs given a choice between diets regulated their intake ratio of protein and carbohydrate with sufficient precision to match their requirements for growth on all choice treatments (Fig. 3). However, specific nutrient intake was highly affected by the combination of diets provided (Fig. 4). This imprecise regulation might be caused by an inherent liking for novel food sources, known as neophilia, which has previously been suggested to be an important mechanism affecting dietary choice in slugs [39-42]. Another explanation could be that slugs consume large amounts of food once a nutrient-rich food source is located. As locomotion in slugs is slow and the distribution of food sources can be highly unpredictable, the slugs may have evolved a behavior of feeding extensively on a food source once located regardless of nutritional imbalances. This would particularly be advantageous if post-ingestive mechanisms can subsequently be applied to rebalance net nutrient gains.

We found strong evidence that $A$. lusitanicus could compensate partially for nutritional imbalances in its diet by increasing or decreasing the utilization efficiency of either nutrient, as well as of total ingested energy (Fig. 6). Similar post-ingestive regulation of protein has been shown in some arthropods [4,43,44], and most likely reflects an ability to use the carbon chains in the proteins for metabolic energy while voiding the amino groups [45]. In response to increased carbohydrate intake, locusts were found to increase respiration in response to feeding on a carbohydrate-rich diet [46]. Similarly, mice increased the mass of brown adhesive tissue to burn off excessive carbohydrate as heat when restricted to a carbohydrate-biased diet [47]. Regulation of the metabolic rate is therefore a plausible mechanism for the post-ingestive regulation of excessive energy intake in A. lusitanicus.

An additional possibility for post-ingestive nutrient regulation is differential absorption of specific nutrients in the gastrointestinal tract. For 
example, the gastrointestinal tract of mice shows a plastic response to diets differing in the ratio of protein to carbohydrate [48], and there is evidence that locusts can absorb nutrients selectively from the gastrointestinal tract by regulating the release of digestive enzymes [49]. We have shown that $A$. lusitanicus possess post-ingestive mechanisms to balance net nutrient gains, but further investigation is needed to reveal the specific mechanisms that are used to regulate nutrients postingestively in A. lusitanicus.

Overall, our study shows that $A$. lusitanicus possesses both behavioral and physiological mechanisms to regulate protein and carbohydrate and, in doing so, the slugs are able to approach the nutritional target for these nutrients. Like A. lusitanicus, invasive species are normally characterized as broad feeding generalists [50-52] and thus feed on a range of foods that are likely to vary in nutrient composition. Our results also suggest, however, that invasive species are likely to be dependent on a more specialized diet with a high proportion of protein in order to support high rates of growth $[37,38]$. This may further explain why invasive species including A. lusitanicus often thrive in cultivated habitats, as these are normally well fertilized with nitrogenous compounds which increases plant protein content $[53,54]$. This prediction could be explicitly tested by applying the geometric framework to related invasive and non-invasive species and comparing nutrient regulation compromises and capabilities and the subsequent effects of nutritional imbalance on performance.

\section{Acknowledgments}

This study was supported by a grant from the UK Biotechnology and Biological Sciences Research Council. D.M. was funded by the Danish Research Council. S.J.S. was funded by a Federation Fellowship and a Laureate Fellowship from the Australian Research Council. J.H. was funded by the Natural Environment Research Council and a University Royal Society Fellowship. We thank Søren Toft and E. Davis Parker for providing laboratory facilities and Kurt Jordaens for advice on maintaining slugs. The authors have no conflict of interest to declare.

\section{Appendix A. Supplementary data}

Supplementary data to this article can be found online at http://dx. doi.org/10.1016/j.physbeh.2013.08.023.

\section{References}

[1] Stephens DW, Krebs JR. Foraging theory. Princeton: Princeton University Press; 1986.

[2] Simpson SJ, Raubenheimer D. The nature of nutrition: a unifying framework from animal adaptation to human obesity. Princeton: Princeton University Press; 2012.

[3] Simpson SJ, Raubenheimer D. A multi-level analysis of feeding behaviour: the geometry of nutritional decisions. Philos Trans R Soc Lond 1993;342:381-402.

[4] Jensen K, Mayntz D, Toft S, Raubenheimer D, Simpson SJ. Nutrient regulation in a predator, the wolf spider Pardosa prativaga. Anim Behav 2011;81:993-9.

[5] Lee KP, Behmer ST, Simpson SJ. Nutrient regulation in relation to diet breadth: a comparison of Heliothis sister species and a hybrid. J Exp Biol 2006;209:2076-84.

[6] Jensen K, Mayntz D, Toft S, Clissold FJ, Hunt J, Raubenheimer D, et al. Optimal foraging for specific nutrients in predatory beetles. Proc R Soc B 2012;279:2212-8.

[7] South S, House CM, Moore AJ, Simpson SJ, Hunt J. Male cockroaches prefer a high carbohydrate diet that makes them more attractive to females: implications for the study of condition dependence. Evolution 2011;65:1594-606.

[8] Raubenheimer D, Simpson SJ, Tait AH. Match and mismatch: conservation physiology, nutritional ecology and the timescales of biological adaptation. Philos Trans R Soc Lond 2012;367:1628-46

[9] Rothman JM, Raubenheimer D, Chapman CA. Nutritional geometry: gorillas prioritize non-protein energy while consuming surplus protein. Biol Lett 2011:7:847-9.

[10] Sørensen A, Mayntz D, Raubenheimer D, Simpson SJ. Protein-leverage in mice: the geometry of macronutrient balancing and consequences for fat deposition. Obesity 2008;16:566-71.

[11] Simpson SJ, Raubenheimer D. Obesity: the protein leverage hypothesis. Obesity 2005;6:133-42.

[12] Lee KP, Simpson SJ, Clissold FJ, Brooks R, Ballard JWO, Taylor PW, et al. Lifespan and reproduction in Drosophila: new insights from nutritional geometry. Proc Natl Acad Sci U S A 2008;105:2498-503.
[13] Fanson BG, Weldon CW, Peréz-Staples D, Simpson SJ, Taylor PW. Nutrients, not caloric restriction, extend lifespan in Queensland fruit flies (Bactrocera tryoni). Aging Cell 2009;8:514-23.

[14] Cotter SC, Simpson SJ, Raubenheimer D, Wilson K. Macronutrient balance mediates trade-offs between immune function and life history traits. Funct Ecol 2011;25:186-98.

[15] Engelke S, Kömpf J, Jordaens K, Tomiuk J, Parker ED. The genetic dynamics of the rapid and recent colonization of Denmark by Arion lusitanicus (Mollusca, Pulmonata, Arionidae). Genetica 2011;139:709-21.

[16] Kozłowski J. The distribution, biology, population dynamics and harmfulness of Arion lusitanicus Mabille, 1868 (Gastropoda: Pulmonata: Arionidae) in Poland. J Plant Prot Res 2007:47:219-30.

[17] Frank T. The role of different slug species in damage to oilseed rape bordering on sown wildflower strips. Ann Appl Biol 1998;133:483-93.

[18] Weidema I. Invasive alien species fact sheet - Arion lusitanicus. Copenhagen: Ministry of the Environment; 2006.

[19] Gren I-M, Isacs L, Carlsson M. Costs of alien invasive species in Sweden. Ambio 2009;38:135-40.

[20] Hulme PE. Handbook of alien species in Europe. Dordrecht: Springer; 2009.

[21] Knop E, Reusser N. Jack-of-all-trades: phenotypic plasticity facilitates the invasion of an alien slug species. Proc R Soc B 2012;279:4668-76.

[22] Hagnell J, Schander C, Proschwitz T. Sniglarne som rör om i trädgårdar och slätktträ. Fauna Flora 2004;99:38-41.

[23] Wittenberg R. An inventory of alien species and their threat to biodiversity and economy in Switzerland. Bern: Federal Office for the Environment FOEN; 2005.

[24] Kozłowski J. Host plants and harmfulness of the Arion lusitanicus Mabille, 1868 slug. J Plant Prot Res 2005;45:221-33.

[25] Keller M, Kollmann J, Edwards PJ. Palatability of weeds from different European origins to the slugs Deroceras reticulatum Müller and Arion lusitanicus Mabille. Acta Oecol 1999;20:109-18.

[26] Briner T, Frank T. The palatability of 78 wildflower strip plants to the slug Arion lusitanicus. Ann Appl Biol 1998;133:123-33.

[27] Kozłowski J, Kozłowska M. Differences in acceptability of herb plants and oilseed rape for slugs (A. lusitanicus, A. rufus and D. reticulatum) in food choice tests. J Plant Prot Res 2008;48:461-74.

[28] Cook RT, Bailey SER, McCrohan CR, Nash B, Woodhouse RM. The influence of nutritional status on the feeding behaviour of the field slug, Deroceras reticulatum (Müller). Anim Behav 2000;59:167-76.

[29] AOAC. Official methods of analysis. Washington: Association of Official Analytical Chemists International; 2006.

[30] O'Brien RG, Kaiser MK. MANOVA method for analyzing repeated measures designs: an extensive primer. Psychol Bull 1985;97:316-33.

[31] Zar JH. Biostatistical analysis. New Jersey: Prentice-Hall; 1999.

[32] Lee KP, Raubenheimer D, Behmer ST, Simpson SJ. A correlation between macronutrient balancing and insect host-plant range: evidence from the specialist caterpillar Spodoptera exempta (Walker). J Insect Physiol 2003;49:1161-71.

[33] Raubenheimer D, Simpson SJ. Nutrient balancing in grasshoppers: behavioural and physiological correlates of dietary breadth. J Exp Biol 2003;206:1669-81.

[34] Lee KP, Behmer ST, Simpson SJ, Raubenheimer D. A geometric analysis of nutrient regulation in the generalist caterpillar Spodoptera littoralis (Boisduval). J Insect Physiol 2002;48:655-65.

[35] Raubenheimer D, Simpson SJ. Integrative models of nutrient balancing: application to insects and vertebrates. Nutr Res Rev 1997;10:151-79.

[36] Jensen K, Mayntz D, Toft S, Raubenheimer D, Simpson SJ. Prey nutrient composition has different effects on Pardosa wolf spiders with dissimilar life histories. Oecologia 2011;165:577-83.

[37] Mooney HA, Mack RN, McNeely JA, Neville LE, Schei PJ, Waage JK. Invasive alien species: a new synthesis. Washington: Island Press; 2005.

[38] Morrison WE, Hay ME. Feeding and growth of native, invasive and non-invasive alien apple snails (Ampullariidae) in the United States: invasives eat more and grow more. Biol Invasions 2011:13:945-55.

[39] Whelan RJ. Response of slugs to unacceptable food items. J Appl Ecol 1982;19:79-87.

[40] Wareing DR. Feeding history: a factor in determining food preferences in slugs. J Molluscan Stud 1993:59:366-8.

[41] Frain MJ, Newell PF. Meal size and a feeding assay for Deroceras reticulatum.J Molluscan Stud 1982;48:98-9

[42] Mølgaard P. Food plant preferences by slugs and snails: a simple method to evaluate the relative palatability of food plants. Biochem Syst Ecol 1986;14:113-21.

[43] Simpson SJ, Raubenheimer D, Behmer ST, Whitworth A, Wright GA. A comparison of nutritional regulation in solitarious- and gregarious-phase nymphs of the desert locust Schistocerca gregaria. J Exp Biol 2002;205:121-9.

[44] Lee KP, Simpson SJ, Raubenheimer D. The effects of nutritional imbalance on compensatory feeding for cellulose-mediated dietary dilution in a generalist caterpillar. J Insect Physiol 2004;50:1171-80.

[45] Zanotto FP, Simpson SJ, Raubenheimer D. The regulation of growth by locusts through post-ingestive compensation for variation in the levels of dietary protein and carbohydrate. Physiol Entomol 1993;18:425-34.

[46] Zanotto FP, Gouveia SM, Simpson SJ, Raubenheimer D, Calder PC. Nutritional homeostasis in locusts: is there a mechanism for increased energy expenditure during carbohydrate overfeeding? J Exp Biol 1997;200:2437-48.

[47] Huang X, Hancock DP, Gosby AK, McMahon AC, Solon SMC, Le Couteur DG, et al. Effects of dietary protein to carbohydrate balance on energy intake, fat storage and heat production in mice. Obesity 2013;21:85-92.

[48] Sørensen A, Mayntz D, Simpson SJ, Raubenheimer D. Dietary ratio of protein to carbohydrate induces plastic responses in the gastrointestinal tract of mice. J Comp Physiol 2010;180:259-66. 
[49] Clissold FJ, Tedder BJ, Conigrave AD, Simpson SJ. The gastrointestinal tract as a nutrient balancing organ. Proc R Soc B 2010;277:1751-9.

[50] Rocha CFD, Anjos LA. Feeding ecology of a nocturnal invasive alien lizard species, Hemidactylus mabouia Moreau de Jonnès, 1818 (Gekkonidae), living in an outcrop rocky area in southeastern Brazil. Braz J Biol 2007;67:485-91.

[51] Haught S, von Hippel FA. Invasive pike establishment in Cook Inlet Basin lakes, Alaska: diet, native fish abundance and lake environment. Biol Invasions 2011;13:2103-14.
[52] Morris JAJ, Akins JL. Feeding ecology of invasive lionfish (Pterois volitans) in the Bahamian archipelago. Environ Biol Fish 2009;86:389-98.

[53] Wang J-J, Tsai JH, Broschat TK. Effect of nitrogen fertilization of corn on the development, survivorship, fecundity and body weight of Peregrinus maidis (Hom., Delphacidae). J Appl Entomol 2006;130:20-5.

[54] Takahashi J, Yanagisawa M, Kono M, Yazawa F, Yoshida T. Influence of the amount of application of nitrogenous fertilizer upon the composition of paddy rice plants. Bull Natl Inst Agric Sci Jpn 1955;4:85-122. 